\title{
Resistance to obesity in Lou/C rats prevents ageing-associated metabolic alterations
}

\author{
D. Perrin ${ }^{1,2}$, C. Soulage ${ }^{1}$, J. M. Pequignot ${ }^{1}$, A. Géloën ${ }^{3}$ \\ ${ }^{1}$ Department of Integrative, Cellular and Molecular Physiology, University Claude Bernard, Lyon, France \\ 2 Department of Cerebral Plasticity, University of Montpellier, France \\ ${ }^{3}$ INSERM/INSA-Lyon, IMBL, Villeurbanne, France
}

\section{Abstract}

Aims/Hypothesis. Ageing is associated with metabolic alterations characterised by changes in energy expenditure, obesity, leptin and insulin resistance. The $\mathrm{Lou} / \mathrm{C}$ rat, an inbred strain of Wistar origin, is presented as both an obesity-resistant rat and a model of healthy ageing.

Methods. To characterise the mechanisms underlying obesity resistance in Lou/C rat, we measured food intake and energy expenditure by indirect calorimetry at $1,6,12,18$, and 24 months of age. Moreover, plasma insulin and leptin concentrations were assessed by radioimmunoassay in Lou/C and Wistar rats throughout their life span.

Results. Compared to Wistar rats, Lou/C rats presented a higher food intake only at 24 months of age and they had a higher energy expenditure at 6 and 12 months of age $(+21 \%$ and $+14 \%$, respectively). Plasma insulin concentration increased markedly in 18- and 24-month-old Wistar rats, but remained stable during ageing in Lou/C rats. From the age of 6 months, the plasma leptin concentrations in Wistar rats were higher than in Lou/C rats of the same age (four-, seven-, five- and threefold higher at 6, 12, 18, 24 months of age, respectively).

Conclusion/interpretation. Compared to Wistar rats, $\mathrm{Lou} / \mathrm{C}$ rats did not develop insulin resistance as confirmed by a higher glucose infusion rate during the hyperinsulinaemic-euglycaemic clamp. These data provide evidence that insulin resistance is associated with the excess of adipose tissue in Wistar rats. Not only Lou/C rats present a higher median life span than Wistar rats $(+20 \%)$, but they also show a healthy ageing process considering fat accretion and insulin resistance. [Diabetologia (2003) 46:1489-1496]

Keywords Insulin resistance, energy expenditure, leptin, ageing, Lou/C rat, food intake.
Ageing is associated with metabolic disorder characterised notably by changes in energy expenditure, fat distribution leading to increased adiposity and insulin resistance.

Several hormones can affect both energy expenditure and fat mass, amongst which are leptin and insu-

Received: 1 April 2003 / Revised: 2 June 2003

Published online: 4 September 2003

(C) Springer-Verlag 2003

Corresponding author: D. Perrin, Department of Integrative, Cellular and Molecular Physiology, UMR-CNRS 5123, University Claude Bernard, 8 avenue Rockefeller, 69373 Lyon Cedex 08, France

E-mail: dav.perrin@netcourrier.com

Abbreviations: IGF1-R, IGF type 1-receptor. lin. Insulin is considered as an adiposity signal. Its plasma concentration is associated with the amount of fat stores $[1,2]$ and insulin receptors are expressed in the brain, especially in the paraventricular nuclei involved in the control of energy intake [3, 4]. Insulin resistance is associated with fat accretion [5] and/or with the effect of ageing on the insulin receptor [6]. Leptin, which is secreted by adipocytes, provides feedback information on the lipid stores towards the hypothalamus. Leptin contributes to the regulation of both food intake and energy expenditure [7, 8]. The plasma leptin concentration is directly related to body fat mass $[9,10]$ but during ageing, increased concentrations of plasma leptin appears dissociated from fat stores [11]. However, it is extremely difficult to differ- 
entiate between ageing and increased fat mass, which is the main determinant of the origin of leptin resistance.

Since adiposity increases during ageing in most rat strains, numerous studies have used caloric restriction in an attempt to discriminate between the process of ageing per se and the effect of fat-mass accumulation on the development of metabolic diseases observed during ageing in rats. Thus, the diminution of visceral fat induced by caloric restriction could counteract the age-associated decrease in hepatic insulin action [12]. Whereas a study [13] using a caloric restriction model concluded that adiposity plays a key role in the development of leptin resistance, another group [14] has suggested that the leptin resistance is not induced by the fat-mass accumulation only. Nevertheless, as the later study has pointed out, the development of leptin resistance in caloric restricted rat could be due to leptin-independent mechanisms activated by chronic caloric restriction. To solve this type of limitation, the metabolic-ageing interaction could be studied in a new and more suitable model, the obese-resistant Lou/C rat. Indeed, the Lou/C rat, an inbred strain of Wistar origin, is presented both as an obesity-resistant rat [15] and as a relevant model of healthy ageing [16]. Whereas the Wistar rat develops spontaneous obesity [17], the Lou/C rat has a lighter body weight and smaller amounts of adipose tissue regardless of age $[15,16,18]$.

Few studies have clarified the origin of obesity resistance of Lou/C rat. Energy accumulation results from the difference between energy input and output. Rats lose their capability to adapt their metabolic rate to maintain their energy balance during ageing [19]. Therefore, the first aim of our study was to compare the metabolic profile between Lou/C and Wistar rats. We characterised energy expenditure by indirect calorimetry and food intake in the obese-resistant Lou/C and Wistar rats at 1, 6, 12, 18, and 24 months. Our second aim was to distinguish the role of the ageing-associated adiposity from that of ageing itself on the development of insulin and leptin resistance. We measured plasma insulin and leptin concentrations in the two strains at each age and insulin resistance was measured by hyperinsulinaemic-euglycaemic clamp at 22 months.

\section{Materials and methods}

Experimental animals. Male Wistar and Lou/C rats (Harlan, Gannat, France) were housed in a temperature-controlled room at $24 \pm 1^{\circ} \mathrm{C}$ with a 12 -h light cycle and were allowed free access to food (AO3, UAR, $3.2 \mathrm{kcal} / \mathrm{g}$ ) and water. All experiments were carried out according to the ethical principles laid down by the French (Ministère de l'Agriculture) and EU Council Directives for care and use of laboratory animals (N 02889).

Measurements of food intake and energy expenditure. Rats were allowed to acclimate in individual cages for 1 week be- fore their food intake was measured. Food intake was monitored daily during the following week from the difference between the amount of food provided and the amount remaining.

Energy expenditure was measured by indirect calorimetry at $26 \pm 1^{\circ} \mathrm{C}$, the thermoneutrality for rats [20]. Oxygen and carbon dioxide concentrations in downstream exhaust gases were successively measured in five different cages. To avoid errors resulting from sequential changes from one cage to another, common parts of the system were rinsed for $90 \mathrm{~s}$, after which gas exchanges were measured for $40 \mathrm{~s}$. A computer-controlled system of three-way valves allowed for sequential analysis of the five cages every $11 \mathrm{~min}$. One cage was left vacant and served as reference for measuring ambient $\mathrm{O}_{2}$ and $\mathrm{CO}_{2}$. Air samples were pumped at a constant flow rate, controlled within strict limit by a mass flowmeter (precision $<1 \%$; Tylan, FM 380 ), and directed to a paramagnetic oxygen analyser (range $0-100 \%$, time delay $<3$ s; Klogor, France) and an infrared carbon dioxide analyser (range $0-1 \%$, time delay $<3 \mathrm{~s}$; Gascard I, Edinburgh Sensors) after being dried through a Permapure system and calcium chloride, which was changed twice daily. The system was calibrated daily with pure nitrogen to set up the zero of the analysers and with a standard gas mixture (CFPO) containing 20.5\% $\mathrm{O}_{2}$ (accuracy 20.44-20.56\%), 0.5\% $\mathrm{CO}_{2}$ (accuracy $0.495-0.505 \%$ ), and $79 \%$ nitrogen to set up the sensitivity. The measuring system was found to be accurate within $0-1 \%$ by bleeding known rates of $\mathrm{CO}_{2}$ and $\mathrm{N}_{2}$, as well as known rates of $\mathrm{O}_{2}$ and $\mathrm{CO}_{2}$. Analog signals from the analysers and mass flowmeter were digitised with an interface card and stored in a desktop computer. After a period of acclimatisation of $24 \mathrm{~h}, \mathrm{O}_{2}$ and $\mathrm{CO}_{2}$ concentrations were measured continuously over $24 \mathrm{~h}$. Thirty minutes were required to calibrate the system, clean the cages, change food and water and weigh the animals. The differences between $\mathrm{O}_{2}$ consumed and $\mathrm{CO}_{2}$ produced in occupied cages and $\mathrm{O}_{2}$ and $\mathrm{CO}_{2}$ concentrations in the empty reference cage, multiplied by the air flow through the cages, yielded the respiratory gas exchanges of animals. Energy expenditures were calculated according to the Depocas and Hart method [21].

Determination of adiposity levels. The weights of adipose tissues were measured at 6 and 24 months of age, afterwards the rats were killed by decapitation. Adiposity was also evaluated by the Lee index, which is the cubic root of body weight in grams divided by the naso-anal length. The Lee index is highly correlated with the percentage of body fat [22].

Noradrenaline content in adipose tissues. The noradrenaline contents was assayed in interscapular brown adipose tissue, retroperitoneal and epididymal adipose tissues of Wistar and Lou/C rats at 6 months of age by high-performance liquid chromatography coupled with electrochemical detection (HPLC-ED).

Interscapular brown adipose tissue, epididymal and retroperitoneal tissues were placed in a convenient volume, related to the weight of tissue, of $0.4 \mathrm{~mol} / \mathrm{l}$ perchloric acid containing $2.7 \mathrm{mmol} / \mathrm{l}$ EDTA-Na $\mathrm{N}_{2}$ and dihydroxybenzylamine as an internal standard. Tissues were subsequently pounded and cooled in an ice bath for $10 \mathrm{~min}$. Thereafter $400 \mu \mathrm{l}$ of $\mathrm{KOH}$-formiate were added and after stirring the resulting homogenate was centrifuged $(3500 \times \mathrm{g}, 10 \mathrm{~min})$. A $0.5 \mathrm{ml}$ aliquot of supernatant was taken and added with $0.5 \mathrm{ml}$ water, $100 \mu \mathrm{l} 0.75 \%$ sodium bisulfite and the $\mathrm{pH}$ was adjusted with $2.8 \mathrm{~mol} / \mathrm{l}$ Tris- $\mathrm{HCl}$ buffer. Thereafter, the mixture was stirred for $20 \mathrm{~min}$ with $20 \mathrm{mg}$ acid-washed alumina, the supernatant discarded and the alumina washed three times with $1 \mathrm{ml}$ each time of rinsing solution containing $14 \mathrm{mmol} / \mathrm{l}$ Tris-HCl, $2.7 \mathrm{mmol} / \mathrm{l}$ EDTA-Na 2 . Catecholamines were then eluted from the alumina with $200 \mu \mathrm{l}$ 
$0.3 \mathrm{~mol} / \mathrm{l}$ perchloric acid containing $1 \mathrm{mmol} / \mathrm{l}$ EDTA-Na $\mathrm{Na}_{2}$ and $1 \mathrm{mg}$ sodium bisulfite per $\mathrm{ml}$. This eluate was stirred $(5 \mathrm{~min})$, centrifuged $(8800 \times g, 15 \mathrm{~min})$ and an aliquot $(10 \mu \mathrm{l})$ subsequently injected into reverse-phase column (Spherisorb ODS2, $5 \mu \mathrm{m}, 125 \mathrm{~mm} \times 4 \mathrm{~mm}$ ) with a mobile phase consisting of $50 \mathrm{mmol} / \mathrm{l}$ citric acid, $50 \mathrm{mmol} / \mathrm{l}$ sodium acetate, $1 \mathrm{mmol} / \mathrm{l} \mathrm{ED}$ TA- $\mathrm{Na}_{2}, 437 \mathrm{mmol} / \mathrm{l}$ acetic acid, $4.3 \mathrm{mmol} / \mathrm{l}$ octane sulfonate and $5 \%$ methanol. The flow rate was $0.9 \mathrm{ml} \cdot \mathrm{min}^{-1}$. Noradrenaline was measured at $+0.67 \mathrm{~V}$ versus the $\mathrm{Ag}^{+} / \mathrm{AgCl}$ reference electrode (ELDEC 102 Chromatofield, Chateauneuf-lesMartigues, France).

Plasma hormone measurements. Insulin and leptin concentrations were measured in the plasma. At each age, blood samples of Wistar and Lou/C rats were collected from the tail vein in microtubes coated with EDTA- $\mathrm{Na}_{2}$. After centrifugation (5000 $\times g$, for $15 \mathrm{~min})$, the plasma were collected, aliquoted and kept at $-80^{\circ} \mathrm{C}$ until assay. Rat leptin and insulin were assessed by radioimmunoassay with a kit purchased from Linco Research (St. Louis, Mo., USA). Fifty $\mu$ l of plasma were used for each measurement. The limit of sensitivity and linearity for the rat leptin assay was 0.5 and $50 \mathrm{ng} / \mathrm{ml}$, respectively and, 0.1 and $10 \mathrm{ng} / \mathrm{ml}$ for the insulin assay.

Hyperinsulinaemic-euglycaemic clamp. Hyperinsulinaemic-euglycaemic clamps were carried out according to [23] except that the clamps were done on awake and unrestrained animals. Animals used for this experimentation were 22 months old. Two polyethylene catheters (EO 3403, Biotrol, Villeron, France) were inserted, one into the right jugular vein and the other into the left carotid under halothane anaesthesia. They were exteriorised through an incision in the nape of the neck and filled with citrate saline. The carotid catheter was used for blood sampling and the jugular one for intravenous infusion. Clamps were conducted at least 4 to 5 days after surgery to allow animals to overcome the surgical stress and to adapt to the cannulation. All animals were deprived of food the night before the hyperinsulinaemic-euglycaemic clamp. Rats were infused with human neutral insulin (Actrapid HM, $40 \mathrm{U} / \mathrm{ml}$, Novo Industry, Denmark) at $6 \mathrm{mU} / \mathrm{kg} \cdot \mathrm{min}$ (in saline plus $1 \%$ albumin fatty acid free) to achieve steady concentrations of plasma insulin. Blood samples of $25 \mu \mathrm{l}$ were collected at 5-min intervals to measure glycaemia (Glucose Analyser II, Beckman) and $100 \mu \mathrm{l}$ of blood were taken at 0,60 and $120 \mathrm{~min}$ of the clamp for insulin measurement by double antibody radioimmunoassay (CIS Bio international, Gif/Yvette, France). Blood glucose was maintained at the basal level $(6 \mathrm{mmol} / \mathrm{l})$ through an adjusted perfusion of glucose solution using a peristaltic roller pump (Gilson). Delivery rates of the pumps were controlled after each clamp. Glucose infusion rate was calculated as the glucose perfused during the second hour of the clamp required to maintain euglycaemia. Results are expressed as $\mathrm{mg}$ glucose per $\mathrm{kg} / \mathrm{min}$ and were considered as a measure of glucose utilisation for the whole body.

Statistics and results expression. All data were analysed with the Statview software (Abacus Concepts Berkeley, Calif., USA). The values are given as means \pm SEM. The organ weights, plasma hormones and food intake values for the Lou/C rats and Wistar rats were compared using ANOVA with two between-subject factors (age and strain). Individual comparisons were done with post-hoc Fischer LSD test when appropriate. Data concerning the energy expenditure were expressed in relation to the metabolic body size as $\mathrm{kg}^{0.67}$ to standardise for differences in body weight [24] and were subjected to two-way ANOVA with one between-subject factor (strain) and one within-subject factor (time). For simple comparison

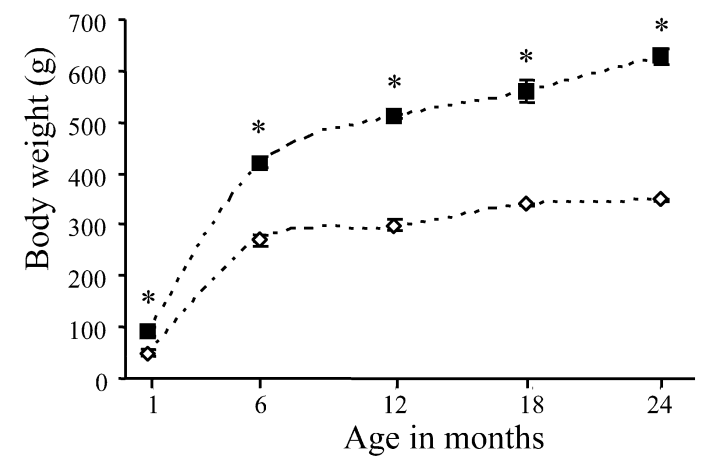

Fig. 1. Body weights of male Wistar rats (solid squares) and Lou/C rats (open losanges) with increasing age. Results are expressed as means \pm SEM. Numbers of animals are 21 for Wistar rats and 25 for Lou/C rats at 1 and 6 months of age, 13 for Wistar rats and 17 for Lou/C rats at 12 and 18 months and four for Wistar rats and five for Lou/C rats at 24 months. *indicates significant statistical difference between the Wistar rats and the Lou/C rats $(p<0.001)$

between two groups, a Student's $t$ test was used. A $p$ value of 0.05 or less was considered for significant differences.

\section{Results}

Body and organ weights. At each age studied, the Lou/C rats presented a lower body weight than the Wistar rats (Fig. 1). The ANOVA indicates a main effect of age $(p<0.0001)$, a main effect of strain $(p<0.0001)$, as well as an age $\times$ strain interaction $(p<0.0001)$. The differences observed were $-46 \%$ $(p<0.0001),-36 \% \quad(p<0.0001), \quad-42 \% \quad(p<0.0001)$, $-39 \%(p<0.0001)$ and $-45 \%(p<0.0001)$ at $1,6,12,18$ and 24 months of age, respectively.

The two strains showed the same weight of interscapular brown adipose tissue at 6 months of age, while a lower weight of inter-scapular brown adipose tissue was noticed in the Lou/C rats at 24 months of age $(-53 \%, p<0.001)$. The more striking weight differences concerned the white adipose tissue. The $\mathrm{Lou} / \mathrm{C}$ rats had less retroperitoneal and epididymal white adipose tissues than the Wistar rats at 6 months of age and these differences were strengthened at 24 months of age (Table 1). Indeed, the weight of retroperitoneal white adipose tissue did not change in Lou/C rats between 6 and 24 months of age but doubled in Wistar rats. Similarly, the amount of epididymal adipose tissue was three- and fourfold lower in Lou/C rats at 6 and 24 months of age, respectively. According to the differences in white adipose amount, we noticed a lower obesity Lee index in Lou/C rats compared to Wistar rats $(-5 \%, p<0.01$ and $-6 \%$, $p<0.01$, at 6 and 24 months of age, respectively).

Energy expenditure and food intake. We noticed in the two strains a marked decrease of food intake calculated independent of body mass by dividing by (body 
Table 1. Body weight, Lee index, adipose tissue weights of Wistar and Lou/C rats at 6 and 24 months

\begin{tabular}{|c|c|c|c|c|}
\hline & \multicolumn{2}{|l|}{6 months } & \multicolumn{2}{|l|}{24 months } \\
\hline & $\begin{array}{l}\text { Wistar rats } \\
n=7\end{array}$ & $\begin{array}{l}\text { Lou/C rats } \\
n=8\end{array}$ & $\begin{array}{l}\text { Wistar rats } \\
n=4\end{array}$ & $\begin{array}{l}\text { Lou/C rats } \\
n=5\end{array}$ \\
\hline Body weight (g) & $423 \pm 16$ & $256 \pm 7 *$ & $622 \pm 24$ & $333 \pm 6^{*}$ \\
\hline Lee index & $302 \pm 2$ & $287 \pm 3 *$ & $309 \pm 3$ & $291 \pm 3 *$ \\
\hline rWAT weight (g) & $8.123 \pm 0.662$ & $1.877 \pm 0.190 *$ & $17.1 \pm 2.2$ & $2.52 \pm 0.47 *$ \\
\hline
\end{tabular}

Data are expressed as means \pm SEM, the number of animals in each group is indicated in column headings $(n)$. *indicates significant statistical difference between Wistar and Lou/C rats

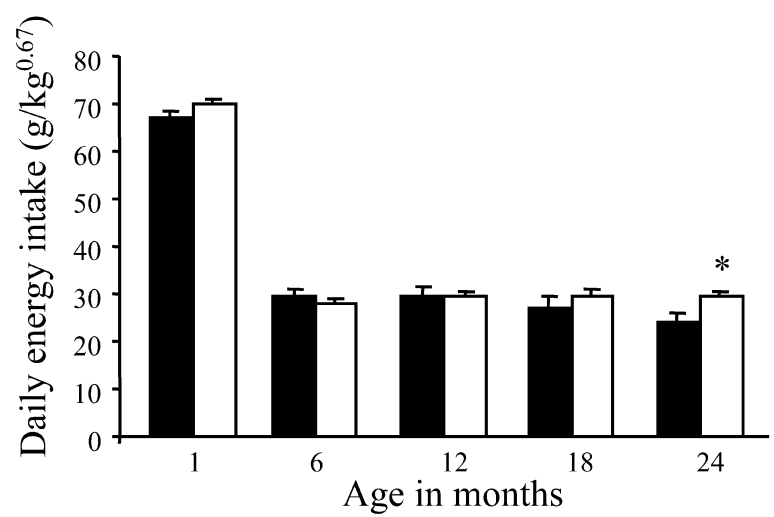

Fig. 2. Daily energy intake of Wistar (black bars) and Lou/C rats (white bars) at 1, 6, 12, 18 and 24 months of age. Results are expressed as means \pm SEM. Numbers of animals are eight for Wistar and LouC rats at 1, 6, 12 an 18 months and four for Wistar rats and six for Lou/C rats at 24 months. *indicates significant statistical difference between the Lou/C rats and the Wistar rats $(p<0.05)$

weight $)^{0.67}$ between 1 and 6 months of age $(-56 \%$, $p<0.0001$ and $-60 \%, p<0.0001$, for the Wistar and the Lou/C rats, respectively; Fig. 2). At the following ages, Wistar rats showed a slight decrease in food intake that led to a lower food intake at 24 compared to 6 months of age $(-19 \%, p<0.05)$. From 6 months of age in the Lou/C rats, we did not notice a main effect of age $(p>0.60)$ on food intake. The daily food intake did not differ significantly during ageing between Wistar and Lou/C rats except at 24 months of age when Lou/C rats showed a higher food intake than Wistar rats $(+23 \%, p<0.05)$.

The energy expenditure expressed per metabolic body mass (J/min.kg0.67) decreased in developing Wistar rats between 1 and 6 months of age and remained constant thereafter (Fig. 3). In Lou/C rats, the decrease of energy expenditure during ageing is more progressive and compared to Wistar rats, we noticed a higher energy expenditure in Lou/C rats at 6 months of age $(+21 \%, p<0.05)$ and at 12 months of age $(+14 \%, p<0.05)$. $(p<0.05)$. rWAT, retroperitoneal white adipose tissue; eWAT, epididymal white adipose tissue; iBAT, interscapular brown adipose tissue

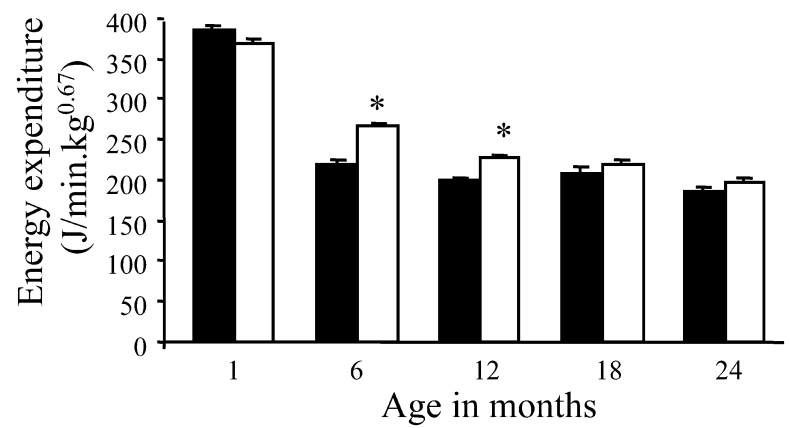

Fig. 3. Daily energy expenditure of Wistar (black bars) and Lou/C rats (white bars) at 1, 6, 12, 18 and 24 months of age. Results are expressed as means \pm SEM. Numbers of animals are eight for Wistar and LouC rats at 1, 6, 12 an 18 months and four for Wistar rats and six for Lou/C rats at 24 months. *indicates significant statistical difference between the Lou/C rats and the Wistar rats $(p<0.05)$

Table 2. Noradrenaline content $\left(\mathrm{pmol} \cdot \mathrm{g}^{-1}\right)$ in adipose tissues at 6 months in Wistar and Lou/C rats

\begin{tabular}{lcll}
\hline & rWAT & eWAT & iBAT \\
\hline Wistar rats & $85.7 \pm 7.2$ & $278.9 \pm 50.9$ & $3092 \pm 394$ \\
Lou/C rats & $158.7 \pm 10.2 *$ & $437.6 \pm 51.7 *$ & $4560 \pm 326^{*}$ \\
\hline
\end{tabular}

The data are expressed as means \pm SEM of eight animals per group. ${ }^{*} p<0.05$ denotes a significant difference between 6month-old Wistar and Lou/C rats. rWAT, retroperitoneal white adipose tissue; eWAT, epididymal white adipose tissue; iBAT, interscapular brown adipose tissue

Noradrenaline adipose tissue. At 6 months of age, Lou/C rats showed an higher noradrenaline content in interscapular brown adipose tissue $(+47 \%, p<0.0001)$, in retroperitoneal and epididymal white adipose tissues (+85\% and $+57 \%, p<0.0001$, respectively) compared to the Wistar rats (Table 2).

Plasma hormone concentrations. Whereas insulin concentration remained stable during ageing in the $\mathrm{Lou} / \mathrm{C}$ rats, there was a marked increase in the 18-month-old Wistar rats that led to a three- to four- 


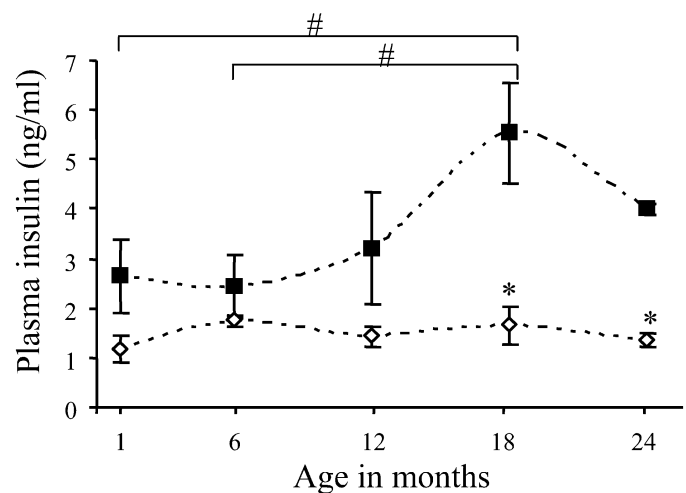

Fig. 4. Plasma insulin concentration of Wistar rats (solid squares) and Lou/C rats (open losanges) at 1, 6, 12, 18 and 24 months of age. Results are expressed as means \pm SEM. Numbers of animals are 9, 6, 8, 7, 4 for Wistar rats and 8, 7, 9, 7, 5 for Lou/C rats at $1,6,12,18$ and 24 months respectively. *indicates significant differences between the Lou/C rats and the Wistar rats $(p<0.05)$. \# indicates significant statistical difference between age in Wistar rats $(p<0.05)$. No main effect of age has been detected in Lou/C rats

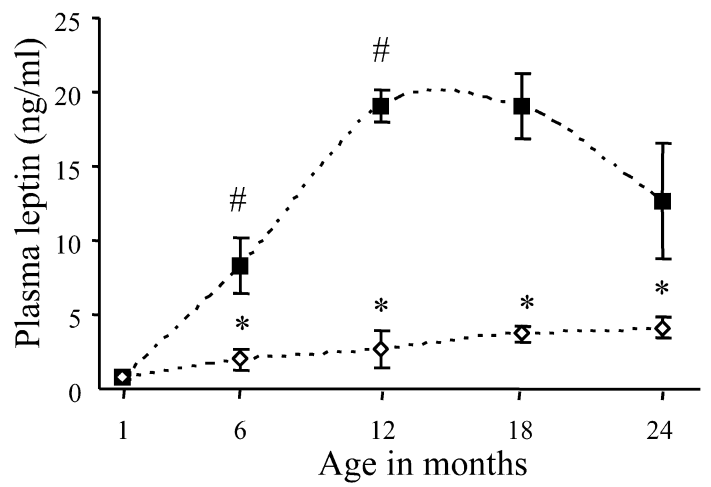

Fig. 5. Plasma leptin concentration of Wistar rats (solid squares) and Lou/C rats (open losanges) at 1, 6, 12, 18 and 24 months of age. Results are expressed as means \pm SEM. Numbers of animals are 10,6, 8, 7, 4 for Wistar rats and 9, 7, 9, 7, 5 for Lou/C rats at 1, 6, 12, 18 and 24 months, respectively. *indicates significant differences between the Lou/C rats and the Wistar rats $(p<0.05)$. \# indicates significant statistical difference between two successive ages $(p<0.05)$

fold higher insulin concentrations in Wistar rats than in Lou/C rats at 18 and 24 months of age (Fig. 4). The plasma leptin concentration (Fig. 5) was characterised by a progressive and limited increase throughout ageing in Lou/C rats that led to a leptin concentration fourfold higher at 24 months of age than at 1 month of age. Wistar rats showed a more sustained increase in leptin concentration that was 22-fold higher at 12 months than at 1 month of age. Thereafter, the leptin concentration tended to decrease until 24 months. From the age of 6 months, the leptin concentrations in Wistar rats were higher than in $\mathrm{Lou} / \mathrm{C}$ rats of the same age (four-, seven-, five- and threefold higher at $6,12,18,24$ months of age, respectively).

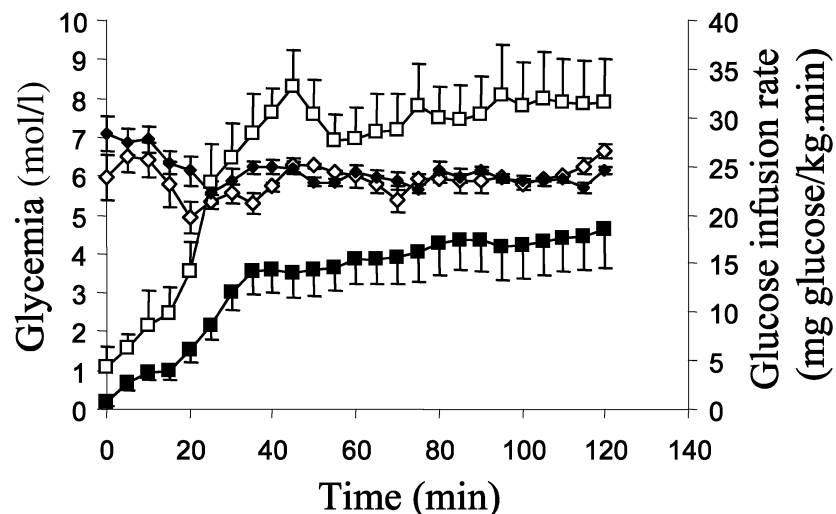

Fig. 6. Insulin sensitivity assessed using an euglycaemic-hyperinsulinaemic clamp in Wistar rats and Lou/C rats at 22 months of age. Results are expressed as means \pm SEM of nine Wistar rats and five Lou/C rats. The plasma glucose concentrations are shown in Wistar rats (solid losanges) and Lou/C rats (open losanges) and the glucose infusion rate are shown in Wistar rats (solid squares) and Lou/C rats (open squares)

Hyperinsulinaemic-euglycaemic clamp. Overnight fasting plasma insulin concentration was $0.92 \pm 0.12$ $\mathrm{ng} / \mathrm{ml}$ in Lou/C rats compared with $1.68 \pm 0.45 \mathrm{ng} / \mathrm{ml}$ Wistar rats at 22 months of age $(p<0.05)$. Basal glucose infusion rate to maintain euglycaemia during exogenous perfusion of $6 \mathrm{mU} / \mathrm{kg} \cdot \mathrm{min}$ insulin was $30.8 \pm 4.0 \mathrm{mg} / \mathrm{kg} \cdot \mathrm{min}$ in $\mathrm{Lou} / \mathrm{C}$ rats versus $16.7 \pm 2.7$ $\mathrm{mg} / \mathrm{kg} \cdot \mathrm{min}$ in Wistar rats $(p<0.05)$ (Fig. 6).

\section{Discussion}

The Lou/C rat has been recently described as a model of successful ageing. Indeed, the Lou/C rats present a median life span (50\% of survivors) of 29 months whereas Wistar rats present a median life span of 24 months and Lou/C rats have a healthier life than Wistar rats $[16,25]$. In agreement with previous reports $[15,16,18]$, we found that this prolonged life span is associated with a reduced and stable adiposetissue mass in Lou/C rat. On the other hand, the Wistar rat has been characterised as a spontaneous model of obesity during ageing [17]. Indeed, the weights of white adipose tissues, especially the weight of retroperitoneal white adipose tissue, whose growth is correlated with the accretion of body lipid [17], are markedly lower in Lou/C compared to Wistar rats. The absence of fat accumulation, confirmed by the lower obesity Lee index measured in Lou/C rats, could be partly explained by the higher energy expenditure noticed at 6 and 12 months of age.

The higher noradrenaline content in retroperitoneal white adipose tissue and epididymal white adipose tissue of the Lou/C rats could lead to an enhanced lypolysis and an inhibition of white adipose tissue development $[26,27]$, resulting in the lower adipose tissue 
weights noticed in the Lou/C rats. These findings suggest an increased mobilisation of the metabolic substrates which allow an increased energy expenditure and a reduced fat-mass.

The interscapular brown adipose tissue is specialised in heat production. The sympathetic nervous system is the major effector of thermogenesis through the release of noradrenaline from nerve endings present in both vessels and adipocytes [28, 29]. In brown adipose tissue, noradrenaline, mainly through $\beta$-receptors, activates proliferation $[30,31]$ and induces the uncoupling protein-1 (UCP-1) expression [32]. UCP-1 uncouples the mitochondrial respiratory chain from oxidative phosphorylation, so that energy, instead of being used for ATP production, is dissipated as heat. Genetically (Zucker) or glutamate-induced obese rats show a reduced activity of the sympathetic nervous system, which participates in the reduced thermogenic function of interscapular brown adipose tissue and in this way contributes to the development of obesity $[33,34,35]$. Thus, the enhanced sympathetic activity in interscapular brown adipose tissue of Lou/C rats could lead to a change in the thermogenic capacity partly accounting for the higher resting metabolism observed in this strain.

Compared to Wistar rats, there is no difference in food intake expressed per unit of metabolic mass in Lou/C rats except at 24 months of age. The higher food intake in old age attests a better general metabolic condition of Lou/C rats than Wistar rats since senescent rats showed a decrease in food intake [36].

Obesity has been linked to the development of several pathologies such as insulin resistance, Type 2 diabetes and cardiovascular diseases. Our study provides evidence that insulin resistance is closely related to the excess of adipose tissue as suggested by the increased insulinaemia and the decreased glucose infusion rate during hyperinsulinaemic-euglycaemic clamp observed in Wistar rats compared to Lou/C rats. Furthermore, Lou/C rat shows a lower leptinaemia than Wistar rat. Leptin is associated with several metabolic risk factors related to the diabesity syndrome $[37,38]$ and plays a causative role in the metabolic decline seen with ageing [39]. Thus, we showed that Lou/C rats not only show a healthy ageing process considering the insulin sensitivity but also probably display healthy ageing considering the leptin related syndrome.

Considering the thermogenic effect of leptin [7] and the increased plasma leptin concentration measured in Wistar rats between 6 and 12 months, we should observe an increased energy expenditure in that group. But, since energy expenditure remained constant between 6 and 24 months in Wistar rats, our study confirms the ageing-associated leptin resistance noticed in this strain $[19,40]$. In addition, our data suggest that Lou/C rats do not develop leptin resistance during ageing. In contrast to the Wistar rats, which presented a rapid and marked increase of plasma leptin concentration as early as 6 months of age, Lou/C rats showed a progressive and weak increase in plasma leptin concentration. Although the increase in plasma leptin concentration observed during ageing is partly due to the development of obesity, this augmentation is disproportionate to the mass of body fat, which suggests leptin resistance $[11,12,22]$. The leptin resistance could result from a diminished density in leptin receptors and an impaired leptin signal transduction [40, 41].

Insulin resistance was attested by the higher glucose infusion rate measured in Lou/C rats compared with Wistar rats, during the hyperinsulinaemic-euglycaemic clamp. Although insulin sensitivity was measured in 22-month-old rats, Wistar rats probably developed insulin resistance at an earlier age. However, since hyperleptinaemia preceded hyperinsulinaemia, leptin could contribute to the development of insulin resistance [42].

The reason why Lou/C rats live longer than Wistar rats has not been determined. A recent study showed that IGF-1 receptor regulates the life span in mice [43]. Of interest, IGF-1 blood concentration is reduced in male and female Lou/C rats [44]. One hypothesis could be that $\mathrm{Lou} / \mathrm{C}$ rats are a natural form of hypopituitarism resulting in low growth hormone and IGF-1 productions. Indeed several similarities exist between Lou/C rats and heterozygous knock-out mice of IGF type 1-receptor (IGF1-R). Both animal models present an increase in longevity. The increase in longevity is greater in female than in male rats (in $\mathrm{Lou} / \mathrm{C}$ rats, the median life span is 29 months for males and 33-34 months for females, [16]). The reduction in body weight is more pronounced in Lou/C versus Wistar rats $(-40 \%)$ compared to the reduction in body weight observed in IGF1-R knock-out mice $(-8 \%)$. The food intake not modified in Lou/C rats and in IGF1-R knock-out mice and the energy expenditure transiently increased only in Lou/C rats compared to Wistar rats, suggest that these metabolic features are not involved in the mechanism of a prolonged life span.

In conclusion, our study provides evidence that Lou/C rats could be considered as a good model of healthy ageing considering metabolic features such as energy balance, insulin and leptin resistance. The lower adiposity observed in Lou/C rats compared to Wistar rats associated with the non-development of insulin resistance in Lou/C rats emphasises the importance of fat accretion on insulin regulation with ageing.

Acknowledgements. This work was supported by the Région Rhône-Alpes (grant "Programme Emergence"). D. Perrin held a fellowship from the Région Rhône-Alpes and C. Soulage was recipient of fellowships from the Ministère de l'Education Nationale, de la Recherche et de la Technologie. 


\section{References}

1. Schwartz MW, Prigeon RL, Kahn SE et al. (1997) Evidence that plasma leptin and insulin levels are associated with body adiposity via different mechanisms. Diabetes Care 20:1476-1481

2. Woods SC, Seeley RJ (2001) Insulin as an adiposity signal. Int J Obes Relat Metab Disord 5:S35-S38

3. Marks JL, Porte D Jr, Stahl WL, Baskin DG (1990) Localization of insulin receptor mRNA in rat brain by in situ hybridization. Endocrinology 127:3234-3236

4. Schulingkamp RJ, Pagano TC, Hung D, Raffa RB (2000) Insulin receptors and insulin action in the brain: review and clinical implications. Neurosci Biobehav Rev 24: 855-872

5. Kohrt WM, Kirwan JP, Staten MA, Bourey RE, King DS, Holloszy JO (1993) Insulin resistance in aging is related to abdominal obesity. Diabetes 42:273-281

6. Lonnroth P, Smith U (1986) Aging enhances the insulin resistance in obesity through both receptor and postreceptor alterations. J Clin Endocrinol Metab 62:433-437

7. Scarpace PJ, Matheny M, Pollock BH, Tumer N (1997) Leptin increases uncoupling protein expression and energy expenditure. Am J Physiol 273:E226-E230

8. Friedman JM, Halaas JL (1998) Leptin and the regulation of body weight in mammals. Nature 395:763-770

9. Maffei M, Halaas J, Ravussin E et al. (1995) Leptin levels in human and rodent: measurement of plasma leptin and ob RNA in obese and weight-reduced subjects. Nat Med 1: 1155-1161

10. Lonnqvist F, Wennlund A, Arner P (1997) Relationship between circulating leptin and peripheral fat distribution in obese subjects. Int J Obes Relat Metab Disord 21:255260

11. Li H, Matheny M, Nicolson M, Tumer N, Scarpace PJ (1997) Leptin gene expression increases with age independent of increasing adiposity in rats. Diabetes 46:20352039

12. Barzilai N, Banerjee S, Hawkins M, Chen W, Rossetti L (1998) Caloric restriction reverses hepatic insulin resistance in aging rats by decreasing visceral fat. J Clin Invest 101:1353-1361

13. Fernandez-Galaz C, Fernandez-Agullo T, Perez C et al. (2002) Long-term food restriction prevents ageing-associated central leptin resistance in wistar rats. Diabetologia 45:997-1003

14. Gabriely I, Ma XH, Yang XM, Rossetti L, Barzilai N (2002) Leptin resistance during aging is independent of fat mass. Diabetes 51:1016-1021

15. Couturier K, Servais S, Koubi H et al. (2002) Metabolic characteristics and body composition in a model of antiobese rats (Lou/C). Obes Res 10:188-195

16. Alliot J, Boghossian S, Jourdan D et al. (2002) The LOU/c/jall rat as an animal model of healthy aging? J Gerontol A Biol Sci Med Sci 57:B312-B320

17. Newby FD, DiGirolamo M, Cotsonis GA, Kutner MH (1990) Model of spontaneous obesity in aging male Wistar rats. Am J Physiol 259:R1117-R1125

18. Veyrat-Durebex C, Alliot J (1997) Changes in pattern of macronutrient intake during aging in male and female rats. Physiol Behav 62:1273-1278

19. Iossa S, Lionetti L, Mollica MP, Barletta A, Liverini G (1999) Energy intake and utilization vary during development in rats. J Nutr 129:1593-1596

20. Gordon CJ (1993) Metabolism. In: Chapman, Hall (ed.) Temperature regulation in laboratory rodents. Cambridge University Press, Cambridge, pp 47-60
21. Depocas F, Hatt JS (1957) Use of Pauling oxygen analyzer for measurement of oxygen consumption of animals in open-circuit system and in short lag closed-circuit apparatus. J Appl Physiol 81:388-392

22. Li H, Matheny M, Tumer N, Scarpace PJ (1998) Aging and fasting regulation of leptin and hypothalamic neuropeptide $\mathrm{Y}$ gene expression. Am J Physiol 275: E405-E411

23. Kraegen EW, James DE, Bennett SP, Chisholm DJ (1983) In vivo insulin sensitivity in the rat determined by euglycemic clamp. Am J Physiol 245:E1-E7

24. Heusner AA (1985) Body size and energy metabolism. Annu Rev Nutr 5:267-293

25. Zimmerman JA, Malloy V, Krajcik R, Orentreich N (2003) Nutritional control of aging. Exp Gerontol 38:47-52

26. Cousin B, Casteilla L, Lafontan M et al. (1993) Local sympathetic denervation of white adipose tissue in rats induces preadipocyte proliferation without noticeable changes in metabolism. Endocrinology 133:2255-2262

27. Youngstrom TG, Bartness TJ (1995) Catecholaminergic innervation of white adipose tissue in Siberian hamsters. Am J Physiol 268:R744-R751

28. Lever JD, Mukherjee S, Norman D, Symons D, Jung RT (1988) Neuropeptide and noradrenaline distributions in rat interscapular brown fat and in its intact and obstructed nerves of supply. J Auton Nerv Syst 25:15-25

29. Lafontan M, Berlan M (1993) Fat cell adrenergic receptors and the control of white and brown fat cell function. J Lipid Res 34:1057-1091

30. Géloën A, Collet AJ, Guay G, Bukowiecki LJ (1988) Betaadrenergic stimulation of brown adipocyte proliferation. Am J Physiol 254:C175-C182

31. Géloën A, Collet AJ, Bukowiecki LJ (1992) Role of sympathetic innervation in brown adipocyte proliferation. Am J Physiol 263:R1176-R1181

32. Rohlfs EM, Daniel KW, Premont RT, Kozak LP, Collins S (1995) Regulation of the uncoupling protein gene (Ucp) by beta 1 , beta 2 , and beta 3 -adrenergic receptor subtypes in immortalized brown adipose cell lines. J Biol Chem 270:10723-10732

33. York DA, Marchington D, Holt SJ, Allars J (1985) Regulation of sympathetic activity in lean and obese Zucker (fa/fa) rats. Am J Physiol 249:E299-E305

34. Rehorek A, Kerecsen L, Muller F (1987) Measurement of tissue catecholamines of obese rats by liquid chromatography and electrochemical detection. Biomed Biochim Acta 46:823-827

35. Blouquit MF, Géloën A, Koubi H, Edwards D, Gripois D (1993) Decreased norepinephrine turnover rate in the brown adipose tissue of pre-obese fa/fa Zucker rats. J Dev Physiol 19:247-251

36. Blanton CA, Horwitz BA, Murtagh-Mark C, Gietzen DW, Griffey SM, McDonald RB (1998) Meal patterns associated with the age-related decline in food intake in the Fischer 344 rat. Am J Physiol 275:R1494-R1502

37. Velasque MT, Bhathena SJ, Hansen CT (2001) Leptin and its relation to obesity and insulin in the SHR/N-corpulent rat, a model of type II diabetes mellitus. Int J Exp Diabetes Res 2:217-223

38. Mark AL, Correia ML, Rahmouni K, Haynes WG (2002) Selective leptin resistance: a new concept in leptin physiology with cardiovascular implications. J Hypertens 20 : 1245-1250

39. Ma XH, Muzumdar R, Yang XM, Gabriely I, Berger R, Barzilai N (2002) Aging is associated with resistance to effects of leptin on fat distribution and insulin action. J Gerontol A Biol Sci Med Sci 57:B225-B231 
40. Fernandez-Galaz C, Fernandez-Agullo T, Campoy F et al. (2001) Decreased leptin uptake in hypothalamic nuclei with ageing in Wistar rats. J Endocrinol 171:23-32

41. Scarpace PJ, Matheny M, Tumer N (2001) Hypothalamic leptin resistance is associated with impaired leptin signal transduction in aged obese rats. Neuroscience 104:1111 $-1117$

42. Ceddia RB, Koistinen HA, Zierath JR, Sweeney G (2002) Analysis of paradoxical observations on the association between leptin and insulin resistance. FASEB J 16: $1163-1176$

43. Holzenberger M, Dupont J, Ducos B et al. (2003) IGF-1 receptor regulates life span and resistance to oxidative stress in mice. Nature 421:182-187

44. Veyrat-Durebex C, Gaudreau P, Coxam V, Gaumet N, Alliot J (1999) Peripheral injection of growth hormone stimulates protein intake in aged male and female Lou rats. Am J Physiol 276:E1105-E1111 